\title{
Life's Little (and Big) Lessons: Identity Statuses and Meaning-Making in the Turning Point Narratives of Emerging Adults
}

\author{
Kate C. McLean \\ University of Toronto
}

\author{
Michael W. Pratt \\ Wilfrid Laurier University
}

\begin{abstract}
A longitudinal study examined relations between 2 approaches to identity development: the identity status model and the narrative life story model. Turning point narratives were collected from emerging adults at age 23 years. Identity statuses were collected at several points across adolescence and emerging adulthood, as were measures of generativity and optimism. Narratives were coded for the sophistication of meaning-making reported, the event type in the narrative, and the emotional tone of the narrative. Meaning-making was defined as connecting the turning point to some aspect of or understanding of oneself. Results showed that less sophisticated meaning was associated particularly with the less advanced diffusion and foreclosure statuses, and that more sophisticated meaning was associated with an overall identity maturity index. Meaning was also positively associated with generativity and optimism at age 23 , with stories focused on mortality experiences, and with a redemptive story sequence. Meaning was negatively associated with achievement stories. Results are discussed in terms of the similarities and differences in the 2 approaches to identity development and the elaboration of meaning-making as an important component of narrative identity.
\end{abstract}

Keywords: identity, narrative, autobiographical memory, adolescence, meaning-making

Identity formation is central to development across the life span but comes to the forefront of developmental concerns in late adolescence and emerging adulthood (e.g., Erikson, 1968). We examined the relationship between the two main approaches to studying identity development: identity statuses and the narrative life story. The personal meaning made of turning point narratives from emerging adults was examined longitudinally in relation to identity statuses, personality, and relevant story characteristics across late adolescence and emerging adulthood. We are aware of only a few studies that are similar to this one and none that have directly examined narrative meaning-making in relation to identity statuses. Because of the common theoretical ancestry of these two approaches, however, it makes sense to examine associations between them.

Notably, the focus of this study was not on comparing two methodologies, though this is inherent in the study design, but was rather to compare two models that have different approaches to understanding how people develop a sense of self. The status

Kate C. McLean, Department of Psychology, University of Toronto, Mississauga, Ontario, Canada; Michael W. Pratt, Department of Psychology, Wilfrid Laurier University, Waterloo, Ontario, Canada.

We thank the young adults who participated in this research and Susan Alistat, Mary Louise Arnold, Natasha Berkeley, Bob Duck, Rob Graham, Cailey Hartwick, Bruce Hunsberger, Kathleen Mackey, Joan Norris, Mark Pancer, and Tracey Ropp for their help with various aspects of the study. This study was supported by Social Sciences and Humanities Research Council of Canada grants to Michael W. Pratt and several colleagues.

Correspondence concerning this article should be addressed to Kate C. McLean, Department of Psychology, Room 2037B, University of Toronto, 2259 Mississauga Road North, Mississauga, Ontario, Canada, L5L 1C6. E-mail: kmclean@utm.utoronto.ca approach focuses on circumscribed life domains and patterns of decisions about those topics, whereas the narrative approach focuses on subjective evaluations and the storying of past experience. Thus, while both approaches derive from Erikson's (1968) theory, there are important differences in the definition of the construct of identity within these approaches.

Erikson (1968) proposed that with the advanced cognitive abilities that come with formal operational thinking and new abilities for perspective taking, adolescents experience increased vulnerability because beliefs and perspectives are ripe for alterations and transformations. Erikson suggested that changes in perspectives and beliefs, coupled with felt vulnerability, set the stage for identity exploration. The manner in which one deals with this identity "crisis" has implications for one's developmental course.

\section{Status Approaches to Identity Development}

Researchers applying status approaches (e.g., Marcia, Waterman, Matteson, Archer, \& Orlofsky, 1993) examine whether someone has struggled with or explored his or her identity (the crisis) and whether he or she has then committed to an identity (the resolution). Methodologically, this line of research began in an interview tradition, and while some still use an interview methodology (e.g., Dunbar \& Grotevant, 2004; Grotevant, 1993; Kroger, 2000), the most widely used method is a self-report survey (e.g., Adams, Bennion, \& Huh, 1989) designed to measure different taxonomies of exploration and commitment.

The logic of the status approach prescribes that the coupling of both exploration and commitment leads to the most advanced form of identity development, identity achievement. The other statuses are moratorium (exploration, no commitment), foreclosure (commitment, no exploration), and diffusion (no commitment, no ex- 
ploration). In reviewing multiple studies, Marcia (1987) reported that those at certain statuses differ in a number of ways. For example, identity achievement is associated with advanced capacities for intimate relationships, psychological flexibility, and resistance to self-esteem manipulation. Moratorium is associated with anxiety, sensitivity to moral issues, and ambivalent family relationships. Foreclosure is associated with authoritarian values and close family relationships. Finally, diffusion is associated with apathy regarding school and relationships, and distanced family relationships. The diffusion and foreclosure statuses are the least developmentally advanced (Marcia et al., 1993).

From the status perspective, a key component to healthy identity development is thinking about and reflecting on one's experiences and options in life, which creates a bridge to narrative theories of identity. However, while status researchers define the construct of identity as an accumulation of thought (or lack of) and active decisions (or lack of) about circumscribed areas of one's life (e.g., Dunbar \& Grotevant, 2004), at the center of narrative theories of identity is the idea that identity is a life story (e.g., McAdams, 1993), an idea to which we now turn.

\section{Narrative Approaches to Identity Development}

While the status approach grew from Erikson's (1968) idea of the management of crisis, the narrative approach grew out of Erikson's emphasis on life span development and psychobiography, as well as other personological writings and approaches to personality development (e.g., Adler, 1927; Murray, 1938). From this perspective, narrative is not just a methodology but is, more importantly, a construct; it is not that the self is measured by assessing stories, but rather the self $i s$ a story. This approach is particularly well suited to the study of identity because it has been suggested that humans have a narrative mode of thought (Bruner, 1990), in which experiences and the self are storied into culturally acceptable and valued narratives that hold currency in one's community and society.

One of the major characteristics of well-formed life stories is a sense of meaning or integration of one's experiences and, thus, of oneself. Researchers have variously defined this narrative characteristic as meaning-making (McLean, 2005; McLean, \& Thorne, 2003; Thorne, McLean, \& Lawrence, 2004), integrative memories (Blagov \& Singer, 2004), integration (e.g., Bauer, McAdams, \& Sakaeda, 2005), exploratory processing (Pals, in press), and accommodation (King, Scollon, Ramsey, \& Williams, 2000). The commonality in these different terms is the use of a form of autobiographical reasoning to think about a life experience (Habermas \& Bluck, 2000).

In a study of self-defining memories, McLean and Thorne (2003) developed a system of examining meaning-making, defining meaning as the report of lessons or insights. Lessons are specific meanings that are often behaviorally driven and are applied only to similar kinds of events in parallel situations. In contrast, insights are broader meanings that extend to other parts of the self beyond those indicated in the narrated event. Narratives that contain any kind of meaning are more likely to be about conflicting or tension-filled events, which suggests that Erikson's (1968) reference to crisis or vulnerability is particularly important to meaning-making (McLean \& Thorne, 2003; Thorne et al., 2004).

McLean and Thorne (2003) conceived of lessons as a developmentally less advanced form of meaning, for which McLean (2005) found evidence in a sample of late adolescents and emerging adults, with younger participants reporting more lessons than older participants. Other researchers have also found that meaningtype processes increase in sophistication with age (e.g., Habermas \& Paha, 2001; McCabe, Capron, \& Peterson, 1991; Pratt, Norris, Arnold, \& Filyer, 1999). Since identity statuses also show development across adolescence and emerging adulthood (Meilman, 1979), the sophistication of identity development advances with age in both approaches, following Erikson's (1968) original formulations.

There is some evidence for connections between meaningmaking and identity statuses, although no study has examined this relationship directly. For example, Mackey, Arnold, and Pratt (2001) found that adolescents with more sophisticated representations of their own and their parents' "voices" in narratives about decision making tended to be at more advanced statuses. Similarly, Sankey and Young (1996) found that those at more advanced statuses narrated their career development experiences in more sophisticated ways. These studies are few and do not directly examine meaning-making, but do suggest that statuses may be related to the narrative sophistication of reports of life experience.

This study examined the relationship between making meaning of life story turning points and identity statuses in emerging adults. Turning points are episodes in which someone undergoes a substantial change (e.g., McAdams, 1993). Bruner (1994) suggested that turning point memories are examples of the process of selfdevelopment, in which the narrative construction of these turning point memories might be more important than what happened in the past event, because the construction of these narratives as major life turning points, rather than the experience itself, is what provides self-understanding. For our purposes, since turning point narratives are usually events in which one understands something new about oneself or faces decisions about different paths to take in life, the emphasis on self-reflection makes these narratives particularly well suited to examine in relation to identity development. In particular, since depth of meaning-making seems especially likely to be related to greater exploration of identity, we expected that the statuses lowest on exploration, diffusion, and foreclosure would be negatively related to narrative meaning.

Our aim in this study was not only to examine the relation between two approaches to identity development, but also to extend recent research on meaning-making, because it is a process that appears central to identity development. Thus, we examined meaning-making in relation to story event types and the narrative sequence of redemption, as well as in relation to dispositional differences in optimism and generativity.

Prior research has found that adolescents' self-defining memories about relationships and mortality events have more meaning in them than memories about achievement and leisure (Thorne et al., 2004). It makes sense that relationship memories are central to meaning-making in adolescence, because relationships undergo profound transformations during this era (e.g., Grotevant \& Cooper, 1985; Youniss \& Smollar, 1985). Mortality events are often about the first time one is faced with personal, or a close other's, 
vulnerability, often leading to an exploration of life and death, thoughts about one's place in the world, or a reevaluation of one's values (Thorne \& McLean, 2002, 2003), which are also experiences that afford opportunities for meaning-making.

We examined mortality, relationship, and achievement events, as well as autonomy events. We added autonomy to our classification scheme because many of the relationship events in this young adult sample appeared to be exclusively about autonomy development as a specific turning point, which makes sense given the importance of autonomy in the process of individuation during this period of the life cycle.

Along with event type, another narrative characteristic that has been robustly associated with meaning is the emotionality of events. As mentioned above, prior research has found that more negative or conflicting events are associated with more meaning (McLean \& Thorne, 2003; Thorne et al., 2004). Some studies have even started from the assumption that negative or difficult life events provide special opportunities for meaning-making (e.g., King et al., 2000; Pals, in press). The association between negative events and meaning-making may exist because disruptive events are more memorable (Rimé, Mesquita, Phillipot, \& Boca, 1991), providing more opportunities for such events to be included in the life story narrative. Events that are conflicting or negative may also provoke a stronger desire to narratively rework the event to reduce cognitive dissonance, and coping and resolution may come in the form of narrative construction (Pals \& McAdams, 2004; Tedeschi \& Calhoun, 2004).

More specifically, recent research on narrative and emotion has focused on the redemptive sequence, when bad turns to good in stories, which may be one process by which negative events are reconstructed to contain meaning. McAdams and colleagues (McAdams, 2004; McAdams, Diamond, de St. Aubin, \& Mansfield, 1997; McAdams, Reynolds, Lewis, Patten, \& Bowman, 2001) have found that those who report more redemptive scenes in their life stories are more generative and have higher well being. McAdams (2004) has argued that redemption is a culturally valued story, so it would make sense that stories with meaning might take the form of redemption.

\section{Personality and Narrative Patterns}

While characteristics of narratives are important to meaning, individual differences in personality may also be associated with the kinds of narratives one constructs (e.g., McAdams et al., 2004; Pals, in press). We examined individual differences in optimism and generativity, expecting both to be related to meaning-making. A generally positive and hopeful outlook on the future is the defining characteristic of optimism. More optimistic people perceive and construct events in a more positive way, which often leads to healthier adjustment (Scheier \& Carver, 1985). More optimistic people tend to persevere with more difficult tasks and use more active, problem-focused coping strategies (Armor \& Taylor, 1998), which may be related to working through important or difficult events using autobiographical reasoning. Pratt and colleagues (Pratt et al., 1999; Pratt, Norris, van de Hoef, \& Arnold, 2001) have also found that optimistic parents tell stories about their children with an emphasis on the child's development and growth, an orientation that may be related to meaning-making.
Overall, then, the desire to see the world in optimistic ways may be partly sustained by constructing meaning-filled stories.

Generativity is another important marker of individual differences in storytelling. Highly generative adults narrate their life stories with a commitment script, which is characterized by a well-defined personal ideology (McAdams et al., 2001). Meaningmaking may be one way that ideology develops, as values, beliefs, and understandings of self, other, and the world may be consolidated and conveyed through meaning-making processes. For example, Pratt et al. (1999) found that high generativity predicted more sophisticated forms of meaning in a life span sample (ages $18-75$ years), regardless of age.

\section{Study Purpose and Hypotheses}

We conducted a longitudinal study spanning late adolescence and emerging adulthood for participants ages 17-23 years. The narrative unit of analysis, turning points, and meaning-making were examined in relation to identity statuses, event types, redemptive story structure, and dispositional optimism and generativity. Our hypotheses were as follows:

1. We expected that identity achievement would be positively associated with increasingly sophisticated forms of meaning and that diffusion and foreclosure would be negatively associated with more sophisticated meaning. We also computed an overall identity maturity index (see Mackey et al., 2001), which we expected to be positively correlated with sophistication of meaning.

2. We expected relationship, autonomy, and mortality events to have more sophisticated meaning than achievement events.

3. We expected that a redemptive story sequence would be associated with more sophisticated meaning.

4. We expected that higher levels of dispositional optimism and generativity would be associated with more sophisticated meaning in turning point stories.

\section{Method}

\section{Participants}

This sample was a volunteer group of 896 adolescents (544 female, $61 \%$ ) drawn from a survey of 16 high schools in central Ontario, Canada Participants completed all parts of an extensive questionnaire given at their schools. They were mostly juniors (mean age $=17.4$ years, $S D=0.80$ ). The majority of participants were White and born in Canada (88\%). Most participants spoke only English at home (82\%), came from intact families (73\%), and reported their family income as average to above average $(94 \%)$

Two years after the original assessment, a follow-up survey was mailed to this original sample. Of the original group, 337 individuals (239 female, $71 \%$ ), representing $38 \%$ of the original sample, completed and returned a questionnaire. The mean age at time of follow-up was 19.2 years $(S D=$ 0.75). The nonparticipants either could not be located or did not return surveys or phone calls.

Six years after the original survey, a third follow-up was conducted of the original full sample. A group of 287 individuals (209 female, $73 \%$ ), 
representing $32 \%$ of the original sample, responded to our request to complete a mail-in questionnaire. The mean age at this time was 23.0 years $(S D=0.75)$. This final follow-up contained the turning point questionnaire. Some of the individuals at the final follow-up did not respond to the turning point story question and so were not included in the analyses below. A total of 200 participants provided turning point stories that could be scored for the final analyses below (146 female, $73 \%$ ).

\section{Procedure}

The original questionnaires were completed in high school classrooms and contained measures of personal adjustment, dispositional optimism, and identity status, as well as a range of other measures (see Jackson, Pratt, Hunsberger, \& Pancer, 2005, for details). Each school/classroom was provided an honorarium of $\$ 2$ per student participant. The second follow-up was 2 years later and included a questionnaire that was mailed to the students who could be located from this sample and who consented over the phone to participate in the second assessment. Completing the questionnaire made students eligible for a $\$ 500$ lottery prize. Four years after the second assessment, a parallel follow-up questionnaire was mailed to all the participants from the original sample who could be located. This questionnaire also included a measure of generative concern, as well as space to write a turning point story. Participants were paid $\$ 10$ for this assessment.

\section{Tasks and Measures}

Demographic measures. Participant age, gender, self-reports of past high school grade averages, family income on a 1 (below average) to 4 (well above average) scale, parents' completed education levels on a 0 (less than grade school) to 6 (postgraduate degree) scale, and family size were all obtained at the first assessment (age 17). Marital status and participants' years of postsecondary education completed were obtained at the final assessment (age 23).

Identity status measure. The Objective Measure of Ego Identity Status (OM-EIS; Adams, Shea, \& Fitch, 1979) was used to measure identity status. This is a 24-item self-report questionnaire, used here with a 9-point Likert scale ranging from 4 (strongly agree) to -4 (strongly disagree). The OM-EIS provides continuous scores for each of the four identity statuses (achieved, moratorium, foreclosed, diffused) measured on the domains of occupation, religion, and politics. To assess the overall relation of identity development to meaning, an index of developmentally advanced identity was also generated, by subtracting scores on the three less advanced statuses of identity diffusion, foreclosure, and moratorium from scores for the most advanced status, identity achievement. This index was termed the identity maturity index (see Mackey et al., 2001). The alphas for the four statuses were modest, ranging from .41 to .66 at age 17 , from .46 to .69 at age 19, and from .48 to .69 at age 23 . Nevertheless, these alphas are comparable to those previously reported for such samples (Adams et al., 1989).

Dispositional optimism. Dispositional optimism was assessed with Scheier and Carver's (1985) Life Orientation Test (LOT). This scale assesses the extent to which people expect positive outcomes in life. The scale's eight items were rated with a 9-point response format, ranging from -4 (very strongly disagree) to 4 (very strongly agree), with higher scores indicating greater optimism. An example item is, "In uncertain times, I usually expect the best." Participants completed the LOT each time they were tested, and Cronbach alphas were $.83, .90$, and .89 , at ages 17,19 , and 23 , respectively.

Generative concern. To measure generative concern at age 23, participants completed the 20-item Loyola Generativity Scale (LGS; McAdams $\&$ de St. Aubin, 1992). This scale was presented on the 9-point response format described for the LOT above. An example item is, "Others would say that I have made important contributions to society." Cronbach's alpha for the LGS at age 23 was .87 .

Turning point narrative. Participants were asked to write about an important transition or change with respect to their understanding of themselves, which constituted the turning point narrative. Participants were able to use as much space as they needed on the written questionnaire.

\section{Narrative Coding}

All reliability coders were blind to the other study data while completing coding.

Meaning-making. Each turning point narrative was coded for meaning by adapting a prior coding system for self-defining memory narratives to these turning point narratives. Prior work has used a mutually exclusive categorical system of no meaning, lesson, or insight (McLean, 2005; McLean \& Thorne, 2001, 2003; Thorne et al., 2004). In examining the turning point narratives in this sample, it was clear that a linear coding system would be more effective at capturing the kind of meaning that these current participants were reporting. Thus, McLean and Thorne's (2001) system was adapted to a linear system (0-3), with increasing scores reflecting increased complexity in autobiographical reasoning. This adaptation converges with other systems for coding the increased complexity of meaning, which have often examined meaning in relation to age, finding that complexity of meaning tends to increase with age (e.g., Habermas \& Paha, 2001; McCabe et al., 1991; McLean, 2005; Pratt et al., 1999), and also converges with McLean and Thorne's (2003) original conceptualization of lessons as a less sophisticated form of meaning than insights.

A score of 0 was given to narratives with no meaning reported. A score of 1 was given to narratives with a lesson reported. As in the original system, lessons were defined as meanings that were often behavioral and did not extend the meaning beyond the original recalled event. For example, a participant reported the following lesson about his career, "I also worked temporarily at a law firm and realized that I did not want to practice law, but wanted to deal with some aspect of the law." This participant indicated thought and behavioral action taken, but without complex reasoning. A score of 2 was given to narratives with vague meaning. These narratives contained meanings that were slightly more sophisticated than lessons but were not as explicit as insights. For example, 1 participant wrote the following narrative, "The event gave me motivation to learn more about medicine as a career and learn much more about myself and my desires in life. I also had to learn to see my own value outside of academics." Finally, a score of 3 was given to narratives with insights, which were defined as meanings that extend beyond the specific event to explicit transformations in one's understanding of oneself, the world, or relationships. For example,

That event led me to choose a career in teaching. I had been planning on law school, but changed my mind. I have started my first job and I love it! Every day is different. I know that I can make a difference by helping each student to see the value of themselves. That boy gave me confidence and I am returning that confidence to others.

The first author completed all coding. A sample of 28 stories were coded for reliability on the $0-3$ scale by an independent rater. Reliability was acceptable, $r(26)=.87$ (exact agreement was $86 \%$ ).

Event type. Turning point narratives were coded for whether the memory event was about relationships, achievement, autonomy, or mortality. The coding of event type in the present study was adapted from Thorne et al.'s (2004) study, such that the present study did not include leisure events and did include autonomy events. Notably, McLean and Thorne (2003) found that relationship events contained separation themes, which appear similar to what was coded here as autonomy. Relationship events focused on an interpersonal encounter, with an emphasis on relational concerns (e.g., falling in love, divorce). Achievement events emphasized effortful 
attempts at mastering vocational, physical, social, or spiritual goals, such as getting into college and excelling at sports, work, or leadership. Autonomy events emphasized becoming independent from others, for example, one's family of origin or peers. Finally, mortality events emphasized one's own or another's mortality, including stories about accidents, death, or near death experiences. Two independent raters coded 40 stories and achieved acceptable levels of reliability (overall $\kappa=.78$; relationship events $\kappa=$ .76; achievement events $\kappa=.82$; autonomy events $\kappa=.71$, mortality events $\kappa=.85$ ).

Story emotional tone. To examine redemptive patterns (negative to positive evaluative story structure), a measure of ending tone (the last half of the story) minus beginning tone (the first half of the story) was calculated, following Pratt et al. (1999), such that positive scores would indicate more redemptive sequences. Story beginnings and endings were both coded on a 1-3 scale from negative tone to positive tone. Interrater reliabilities between two independent raters for a sample of 45 stories were $r(43)=.74$ for story beginnings (exact agreement was $87 \%$ ) and $r(43)=$ .71 for story endings (exact agreement was $87 \%$ ).

\section{Results}

\section{Descriptive Statistics}

The sample comprised 200 participants with turning point stories at age 23 that could be scored for meaning-making and who had completed at least one of the prior assessments. There were no differences in meaning-making scores based on participant age, gender, self-reported high school grade point average at age 17, completed parent education level, years of university/college completed, self-reported family income, family size, or marital status at age 23 .

Means for the measures used are shown in Table $1 .^{1}$ The written turning point stories averaged $120.9(S D=63.8)$ words. The mean score for meaning-making was $1.84(S D=1.24)$. Story length was associated with meaning, $r(192)=.23, p<.01$, suggesting that meaning-making may be associated with more elaborated narratives.

\section{Central Analyses}

Identity statuses and meaning. As can be seen in Table 2 and as predicted, meaning in the turning point stories at age 23 was negatively correlated with identity foreclosure at age 17 but, unexpectedly, was not related to diffusion or achievement at age 17 . As predicted, age 23 meaning-making was negatively correlated with age 19 diffusion, but not with foreclosure or achievement at age 19. Meaning at age 23 was negatively related to age 19 moratorium. At age 23, as predicted, meaning was negatively correlated with both diffusion and foreclosure but, unexpectedly, not with achievement. As predicted, the identity maturity index at each age was positively associated with meaning at age 23 .

Event types. Seventy-three stories were classified as achievement events (36\%), 66 as relationship events (33\%), 31 as autonomy events (16\%), and 26 as mortality events (13\%). Four stories were coded as "other," and were usually brief, ambiguous stories (e.g., "I grew up."). There were significant differences for meaning-making and event type, $F(3,190)=4.16, p<.01$. Post hoc Scheffé tests showed that the significant differences $(p<.05)$ were between the achievement $(M=1.52, S D=1.17)$ and mortality stories $(M=2.38, S D=1.02)$. The mean for relation-
Table 1

Means, Standard Deviations, and Ranges for All Variables

\begin{tabular}{|c|c|c|c|c|}
\hline Variable & $N$ & $M$ & $S D$ & $\begin{array}{c}\text { Possible } \\
\text { range }\end{array}$ \\
\hline Story length (words) & 194 & 120.89 & 63.85 & $16-565$ \\
\hline Meaning & 200 & 1.84 & 1.24 & $0-3$ \\
\hline \multicolumn{5}{|l|}{ Emotional tone } \\
\hline Beginning & 199 & 0.65 & 0.55 & $0-2$ \\
\hline End & 199 & 1.63 & 0.55 & $0-2$ \\
\hline Age 23 LGS & 199 & 66.38 & 10.00 & $20-100$ \\
\hline \multicolumn{5}{|l|}{ LOT } \\
\hline Age 17 & 192 & 46.89 & 12.50 & $8-72$ \\
\hline Age 19 & 142 & 48.31 & 13.45 & $8-72$ \\
\hline Age 23 & 198 & 51.53 & 12.80 & $8-72$ \\
\hline \multicolumn{5}{|l|}{ Diffusion } \\
\hline Age 17 & 191 & 28.98 & 8.06 & $6-54$ \\
\hline Age 19 & 140 & 28.12 & 8.04 & $6-54$ \\
\hline Age 23 & 199 & 26.97 & 8.43 & $6-54$ \\
\hline \multicolumn{5}{|l|}{ Foreclosure } \\
\hline Age 17 & 191 & 19.54 & 8.53 & $6-54$ \\
\hline Age 19 & 140 & 18.85 & 8.15 & $6-54$ \\
\hline Age 23 & 199 & 15.99 & 7.74 & $6-54$ \\
\hline \multicolumn{5}{|l|}{ Moratorium } \\
\hline Age 17 & 190 & 30.12 & 9.39 & $6-54$ \\
\hline Age 19 & 141 & 30.08 & 7.57 & $6-54$ \\
\hline Age 23 & 199 & 25.92 & 8.15 & $6-54$ \\
\hline \multicolumn{5}{|l|}{ Achievement } \\
\hline Age 17 & 190 & 37.37 & 7.77 & $6-54$ \\
\hline Age 19 & 141 & 37.72 & 7.03 & $6-54$ \\
\hline Age 23 & 199 & 37.54 & 7.22 & $6-54$ \\
\hline
\end{tabular}

Note. $\quad$ LGS $=$ Loyola Generativity Scale LOT $=$ Life Orientation Test

ship stories was $1.94(S D=1.29)$, and the mean for autonomy stories was $2.13(S D=1.20)$.

Redemption. As expected, the redemptive sequence in age 23 turning point stories was correlated with meaning-making, $r(199)=.23, p<.001$. This result was based on the fact that beginning and end story tone were also differentially related to meaning in expected directions. Emotional tone of the initial story events was negatively related to meaning-making, $r(197)=-.11$, $p=.06$, and end story tone was positively related to meaningmaking, $r(197)=.15, p<.05$.

Optimism and generativity. There were no significant associations between meaning-making at age 23 and optimism at ages 17 and 19 . At age 23 , however, meaning was associated positively with optimism on the LOT, $r(196)=.16, p<.05$, and with generativity on the LGS, $r(197)=.18, p<.05$.

\footnotetext{
${ }^{1}$ We conducted an analysis of consistency and change on the identity status measure for those who reported data at each time of testing $(n=$ 140). Each of the four statuses showed stability over time, with positive correlations ranging from .42 to .56 for diffusion, from .53 to .59 for foreclosure, from .29 to .48 for moratorium, and from .14 to .35 for achievement across the three times of testing. Stabilities for the total identity index measure were $.50, .39$, and .53 , for ages 17 and 19 , ages 17 and 23 , and ages 19 and 23, respectively (all $p s<.001$ ). In terms of developmental change, for diffusion, there was a borderline decrease across time $(p<.10)$. For both foreclosure and moratorium statuses, there were significant decreases over time $(p s<.05)$, but there were no significant changes in identity achievement. The summary identity index became significantly less negative across this period $(p<.05)$.
} 
Table 2

Correlations of Meaning-Making at Age 23 and Identity Statuses Across Three Ages

\begin{tabular}{cccccc}
\hline Age & Diffusion & Foreclosure & Moratorium & Achievement & Maturity index \\
\hline $17(n=189)$ & -.09 & $-.14 *$ & .02 & .12 & $.13 \dagger$ \\
$19(n=138)$ & $-.15 \dagger$ & -.11 & $-.14 \dagger$ & .03 & $.20^{*}$ \\
$23(n=197)$ & $-.22^{* *}$ & $-.18^{* *}$ & -.07 & .07 & $.20^{* *}$ \\
\hline$\dagger p<.10 . \quad * p<.05 . \quad * * p<.01$. & & &
\end{tabular}

To summarize these effects for meaning-making, regression analyses were conducted. As shown in Table 3, the identity status measure was generally unrelated to other predictors, except that female participants scored higher on the identity status measure at age 17 . With respect to the personality measures, more advanced identity at age 23 was modestly positively associated with greater generativity at age 23; as well, identity status totals were modestly associated with optimism on the LOT. A redemptive story sequence was also associated with generativity and optimism at age 23, and optimism and generativity were also positively correlated, as expected. Only one correlation exceeded .30 (optimism and generativity at age $23, r=.56$ ), however, suggesting that collinearity problems were not substantial in this set of predictors.

Because the identity index scores were quite highly correlated across ages, however, as was optimism, it was not appropriate to enter parallel measures from different testing times into the same regression because of collinearity. Consequently, we entered the predictor variables into three different regressions, one for each time of testing, with meaning-making at age 23 as the outcome. For each age regression, we entered gender, high school grades, and word count as control variables in a first block, and we then entered story redemption, personality variables, and the identity index as a second block (see Table 4). Word count and redemptive story sequence were significant positive predictors in all of the equations (word count was only a borderline predictor for the age 19 regression, as shown). For both age 23 and age 19, the identity maturity index term was a significant positive predictor of meaning-making after word count and story structure were controlled. Dispositional optimism at each age and generativity at age 23 were not significant in the final equations.

\section{Narrative Examples}

To illustrate the kinds of narratives that come from people at different identity statuses, we present two narrative examples. The first comes from Nadine, ${ }^{2}$ who received a 0 on the meaning scale and received high scores on diffusion and foreclosure.

\footnotetext{
When I told my boyfriend that I loved him over 2 years ago. We were in a park after having a terrific day (previous day) at Niagara Falls. I asked him if yesterday could have been better. He said no, and I said yes, if I had only told him what I have been thinking and feeling (that I loved him). I was scared to have those words leave my mouth; never been in love before. Wasn't sure what it felt like, what to expect when it was said. Knew that those three words could never be taken back. My boyfriend said he loved me too. We have been together for over $21 / 2$ years with plans for marriage.
}

This narrative shows no explicit efforts toward making meaning of the relationship or herself within the relationship. After this event, it appears that there was no reflection about the upcoming marriage, perhaps signifying a foreclosed response to this opportunity for identity development.

The second narrative comes from Madeline, who scored low on diffusion and foreclosure and received a 3 on the narrative meaning scale. Meaning is in italics.

At the end of this summer, I left Canada for Scotland in order to pursue teaching education. This is something that I had planned on for a long time and was very sure about. I had been away from home before, but never as far away as another country. Although I only half completed the length of my time here, I have learned a great deal about myself that I didn't really see before. I have certainly proved that I am very independent. I had previously doubted this about myself. It felt rather fulfilling to feel such independence. I had the occasional doubt prior to coming here that it would be difficult, but little doubt exists in my mind now.

In this autonomy story, Madeline has reflected on an experience that changed her in an explicit way. She has a new feeling of independence and appears to have found a path in life after exploring herself and her options, a sign of a well-developed life story and movement toward an achieved identity.

\section{Discussion}

This study showed that meaning is more characteristic in its absence from turning point stories in emerging adulthood for those at lower levels of identity status development rather than in its presence at more advanced levels. Findings for the maturity index, however, suggest that meaning may be representative of more advanced identity development but only in a broader scope, not at the individual status level. In terms of story characteristics, this study converges with previous research, showing that different event types afford more opportunities for meaning-making and that redemption as a story structure is associated with meaning. Finally, relations between personality and story characteristics help to elaborate how individual differences in story construction may be important to narrative identity.

This study examined the two major approaches to studying identity development: identity statuses and the narrative life story. Status approaches to identity focus on the dimensions of exploration and commitment across different life domains (Marcia et al., 1993). The life story approach focuses on the self as a story, with different narrative characteristics representing different patterns of self-development (e.g., McAdams, 1993). We found an interpretable, but modest, association between these two types of con-

\footnotetext{
${ }^{2}$ All names are pseudonyms.
} 
Table 3

Intercorrelations of Various Predictor Variables

\begin{tabular}{|c|c|c|c|c|c|c|c|c|c|c|c|c|}
\hline Variable & 1 & 2 & 3 & 4 & 5 & 6 & 7 & 8 & 9 & 10 & 11 & 12 \\
\hline 1. Word count & - & & & & & & & & & & & \\
\hline 2. Sex & .01 & - & & & & & & & & & & \\
\hline 3. Grade point average & $.16^{*}$ & $.16^{*}$ & - & & & & & & & & & \\
\hline 4. Redemption & .00 & .02 & .00 & - & & & & & & & & \\
\hline 5. LGS (age 23) & $.15^{*}$ & $.21 *$ & -.08 & $.26^{* *}$ & - & & & & & & & \\
\hline 6. LOT (age 23) & .11 & .05 & .06 & $.22 *$ & $.56 * * *$ & - & & & & & & \\
\hline 7. LOT (age 19) & .06 & .04 & .04 & .15 & $.27 * *$ & $.50 * * *$ & - & & & & & \\
\hline 8. LOT (age 17) & .04 & -.05 & .08 & .10 & $.28 * *$ & $.44 * * *$ & $.63 * * *$ & - & & & & \\
\hline 9. Maturity index (age 23) & .10 & -.01 & .13 & .09 & $.22 *$ & $.30 * *$ & $.18 *$ & .10 & - & & & \\
\hline 10. Maturity index (age 19) & .08 & .02 & -.08 & .03 & .01 & .15 & $.28 * *$ & $.18 *$ & $.53 * * *$ & - & & \\
\hline 11. Maturity index (age 17) & .07 & $.19 *$ & .07 & .03 & .14 & .14 & $.22 *$ & $.27 *$ & $.39 * * *$ & $.50 * * *$ & - & \\
\hline 12. Meaning & $.23^{* *}$ & .03 & .03 & $.20 *$ & $.18^{*}$ & $.16^{*}$ & .08 & .08 & $.20 * *$ & $.20 *$ & .13 & - \\
\hline
\end{tabular}

Note. For sex, $1=$ male, $2=$ female (biserial correlations); LGS $=$ Loyola Generativity Scale; LOT $=$ Life Orientation Test.

$* p<.05 . \quad * * p<.01 . \quad * * * p<.001$.

structs, namely that narrative meaning is more important in its absence from lower identity statuses than its presence at higher statuses. The statuses low on identity exploration, diffusion and foreclosure, were most consistently negatively related to story meaning (see Table 2). Our longitudinal data also showed that identity statuses (diffusion and the maturity index) measured in late adolescence (age 19) were related to later meaning-making in emerging adulthood (age 23). This latter longitudinal finding is important, since these results suggest that if identity exploration has begun by age 19, this may then propel people forward toward more reflective meaning-making processes in the development of the life story at age 23 . We cannot be sure that this is a causal trajectory because of the correlational nature of these data, but our longitudinal results are important in showing continuity from one aspect of identity development to another over time.

While there is thus some important predictable convergence in these two approaches to identity, there is also a significant degree

Table 4

Regression Analyses Predicting Meaning Scores at Age 23 From Control, Narrative and Personality Variables at Ages 17, 19, and 23

\begin{tabular}{lccc}
\hline & \multicolumn{3}{c}{ Model $2 \beta$} \\
\cline { 2 - 4 } \multicolumn{1}{c}{ Variable } & Age 17 & Age 19 & Age 23 \\
\hline Word count & $.20^{*}$ & $.15 \dagger$ & $.20^{*}$ \\
Gender & -.01 & .05 & -.01 \\
Grades & .00 & .03 & -.02 \\
Redemption & $.20^{*}$ & $.26^{*}$ & $.18^{*}$ \\
LOT & .03 & -.04 & .02 \\
LGS at age 23 & - & - & .01 \\
Maturity index & .11 & $.24^{*}$ & $.16^{*}$ \\
\hline
\end{tabular}

Note. Final equation for age 17: $F(6,169)=3.26, p<.01 ; R^{2}=.10$. Final equation for age 19: $F(6,121)=3.45, p<.01 ; R^{2}=.15$. Final equation for age $23: F(7,168)=3.20, p<.01 ; R^{2}=.12$. Block $1=$ control variables: word count, gender, grades; Block $2=$ redemptive sequence, LOT, maturity index. Dashes indicate that the LGS was not administered. LOT $=$ Life Orientation Test; LGS = Loyola Generativity Scale. $\dagger p<.10 . * p<.05$. of divergence, suggesting that each approach appears to offer a distinctive lens to the study of identity. One way to understand the distinction between the two approaches may be in their emphasis on the objective and the subjective in identity development. In the status approach, domains (e.g., religion) are chosen a priori and imposed on participants in a structured response format. In the life story approach, the topics of identity are self-chosen; participants select which particular experiences are important to them. This distinction is large and is a likely candidate for explaining our modest level of associations between frameworks. For example, someone may report that he or she has thought about and decided on a political stance (identity achievement), but that political stance may not have a high degree of personal importance and so may not emerge in one's life story at all. The life story may also be more integrated, in some respects, and statuses may be varied across different cognitive domains (a major reason why alphas for the identity status measures across domains are only modest, as found in the present study).

Turning to the analyses within narratives, using different samples and different narrative elicitations but similar coding systems, several studies have now shown that the type of event is important to whether late adolescents and emerging adults report meaning in their narratives. Thorne et al. (2004) found that relationship and mortality events had the most meaning in late adolescents' selfdefining memory narratives compared with achievement and leisure events. Building on those findings, the present study again found mortality events to be of primary relevance to meaning filled memories and found achievement events to be less relevant. Together, these findings suggest that relationship, autonomy, and mortality events appear to be most ready for meaning-making during a stage in which the life story is beginning to be formed. The development of autonomy and connectedness and the recognition of one's own limitations and vulnerabilities may be at the heart of inspiration for life story development.

Now that there is convergence across studies, it is important to address the lack of meaning in achievement stories. Many of the achievement turning points were about career or vocational choices, as well as school and athletic achievements. One possibility is that career and vocational paths may be chosen for people 
or that they may be chosen before much reflection or exposure to options occurs (e.g., at the beginning of college). Achievement events, especially the types commonly reported in our study, such as graduations, may also be more scripted by formalized expectations in communities; one does not need to make sense of something that is expected. ${ }^{3}$ Achievements are an important part of who one is, evidenced by their being reported as self-defining and turning point memories, but these events do not appear to demand much personal meaning-making.

In terms of emotion, this study converges with others, showing that the redemptive story sequence is associated with meaning (see Pratt et al., 1999), although we note that our correlations were quite modest. The management of difficult life events by using meaning-making processes to find the good within the bad is important to the development of a healthy narrative identity (McAdams, 2004; Pals \& McAdams, 2004). McAdams (2004) has proposed that the redemptive self is a culturally based phenomenon. Thus, this finding may have more to do with the value of different kinds of stories in cultural communities, rather than the objective emotional sequence, which may have different meanings among other groups (e.g., Wang, 2004).

While the prior discussion has focused on characteristics of the narratives that were related to meaning, there were also personal characteristics that were related to narration and to story construction. We found that higher dispositional optimism and generativity were associated with more sophisticated forms of meaning at age 23. The connection between meaning and optimism may be related to finding the benefit in negative events (King et al., 2000; McAdams et al., 2001; Pals \& McAdams, 2004); however, our regression analyses showed that the connection between personal optimism, generativity, and meaning may be carried largely by the relation of personality to redemptive story structure. Perhaps personality influences on identity development take the path of shaping narrative patterns and sequencing, which suggests that a narrative analysis helps to see how aspects of identity unfold. The complexity of the relations among traits, narratives, and identity still needs further work, but these analyses suggest that a narrative approach may be particularly important in understanding the relation between traits and identity processes (see also Pals, in press).

We now present several limitations of this study and then some general conclusions. First, while turning point narratives may be particularly useful in examining identity development, especially before the life story is fully formed, there may be limitations to focusing on them as well. We might expect to find more robust associations between statuses and narrative patterns in a complete life story because that narrative would necessarily encompass a much fuller view of the person. Second, collecting narratives and survey assessments at each age would help tease apart issues of age-developmental trends, possible causal ordering, as well as method and time effects. Third, the lack of high concordance between these approaches to identity may be due partly to method. If we had assessed identity statuses with the status interview, we might have seen a higher convergence between meaning-making and statuses. The reliability of the OM-EIS instrument was also modest and may have weakened any effects. Fourth, further exploration of other life story dimensions in relation to statuses is also warranted. For example, the coherence of life stories might be particularly limited by a lack of commitment, so that stories from foreclosed individuals might be quite coherent, but relatively shallow in meaning, as was observed here. Finally, cultural differences in narration were not addressed, as our samples were fairly homogeneous. Differences in narrative patterns that are reflective of identity development should be examined in future research, because what constitutes meaning may differ by cultural group (e.g., Wang, 2004).

In conclusion, this study provides the first evidence that two distinct approaches to identity development hold some degree of predictable convergence. Those low in identity exploration tended to show less narrative meaning in their personal turning point stories. Yet the correlations in this study were modest, which leads us to conclude that the lack of strong overlap likely represents some distinctiveness in these two approaches. Identity statuses reflect broad dimensions of exploration and commitment in specific and objective domains and across many experiences in our lives. The stories we live by reflect subjectively recalled, specific, and vivid experiences, drawn together into a life narrative. This study suggests that a lack of personal exploration in identity development and life stories lacking in meaning is the crux of where these two paths come together. Overall, it does appear that Erikson's (1968) wise ideas about the psychosocial construction of identity have filtered down through these two distinctive research paths, and yet may meet and complement each other in some important ways.

${ }^{3}$ We thank an anonymous reviewer for suggesting this interpretation.

\section{References}

Adams, G. R., Bennion, L., \& Huh, K. (1989). Objective measure of ego identity status: A reference manual. Logan, UT: Utah State University.

Adams, G. R., Shea, J., \& Fitch, S. A. (1979). Toward the development of an objective assessment of ego-identity status. Journal of Youth and Adolescence, 8, 223-237.

Adler, A. (1927). The practice and theory of individual psychology. New York: Harcourt Brace World.

Armor, D. A., \& Taylor, S. E. (1998). Situated optimism: Specific outcome expectancies and self-regulation. In M. P. Zanna (Ed.), Advances in experimental social psychology (Vol. 30, pp. 309-379). New York: Academic Press.

Bauer, J. J., McAdams, D. P., \& Sakaeda, A. R. (2005). Interpreting the good life: Growth memories in the lives of mature, happy people. Journal of Personality and Social Psychology, 88, 203-217.

Blagov, P. S., \& Singer, J. A. (2004). Four dimensions of self-defining memories (specificity, meaning, content, and affect) and their relationships to self-restraint, distress, and repressive defensiveness. Journal of Personality, 72, 481-512.

Bruner, J. S. (1990). Acts of meaning. Cambridge, MA: Harvard University Press.

Bruner, J. S. (1994). The remembered self. In U. Neisser \& R. Fivush (Eds.), The remembering self: Construction and accuracy in the selfnarrative (pp. 41-54). New York: Cambridge University Press.

Dunbar, N., \& Grotevant, H. D. (2004). Adoption narratives: The construction of adoptive identity during adolescence. In M. W. Pratt \& B. H. Fiese (Eds.), Family stories and the life course: Across time and generations (pp. 135-161). Mahwah, NJ: Erlbaum.

Erikson, E. H. (1968). Identity, youth, and crisis. New York: Norton.

Grotevant, H. D. (1993). The integrative nature of identity: Bringing the 
soloists to sing in the choir. In J. Kroger (Ed.), Discussions on ego identity (pp. 121-146). Hillsdale, NJ: Erlbaum.

Grotevant, H. D., \& Cooper, C. R. (1985). Patterns of interaction in family relationships and the development of identity exploration in adolescence. Child Development, 56, 415-428.

Habermas, T., \& Bluck, S. (2000). Getting a life: The emergence of the life story in adolescence. Psychological Bulletin, 126, 248-269.

Habermas, T., \& Paha, C. (2001). The development of coherence in adolescents' life narratives. Narrative Inquiry, 11, 35-54.

Jackson, L., Pratt, M. W., Hunsberger, B., \& Pancer, S. M. (2005). Optimism as a mediator of relations between perceived parental authoritativeness and adjustment among adolescents: Finding the sunny side of the street. Social Development, 14, 273-304.

King, L. A., Scollon, C. K., Ramsey, C., \& Williams, T. (2000). Stories of life transition: Subjective well-being and ego development in parents of children with Down syndrome. Journal of Research in Personality, 34, 509-536.

Kroger, J. (2000). Identity development: Adolescence through adulthood. Thousand Oaks, CA: Sage.

Mackey, K., Arnold, M. L., \& Pratt, M. W. (2001). Adolescents' stories of decision-making in more or less authoritative families: Representing the voices of parents in narrative. Journal of Adolescent Research, 16, 243-268.

Marcia, J. E. (1987). The identity status approach to the study of ego identity development. In T. Honess \& K. Yardley (Eds.), Self and identity: Perspectives across the lifespan (pp. 161-171). Boston: Routledge \& Kegan Paul.

Marcia, J. E., Waterman, A., Matteson, D., Archer, S., \& Orlofsky, J. (1993). Ego identity: A handbook for psychosocial research. New York: Springer-Verlag.

McAdams, D. P. (1993). The stories we live by: Personal myths and the making of the self. New York: William Morrow.

McAdams, D. P. (2004). The redemptive self: narrative identity in America today. In D. R. Beike \& J. M. Lampinen (Eds.), The self and memory. Studies in self and identity (pp. 95-115). New York: Psychology Press.

McAdams, D. P., Anyidoho, N. A., Brown, C., Huang, Y. T., Kaplan, B., \& Machado, M. A. (2004). Traits and stories: Links between dispositional and narrative features of personality. Journal of Personality, 72, 761-784.

McAdams, D. P., \& de St. Aubin, E. (1992). A theory of generativity and its assessment through self-report, behavioral acts, and narrative themes in autobiography. Journal of Personality and Social Psychology, 62, 1003-1015.

McAdams, D. P., Diamond, A., de St. Aubin, E., \& Mansfield, E. (1997). Stories of commitment: The psychosocial construction of generative lives. Journal of Personality and Social Psychology, 72, 678-694.

McAdams, D. P., Reynolds, J., Lewis, M., Patten, A., \& Bowman, P. J. (2001). When bad things turn good and good things turn bad: Sequences of redemption and contamination in life narrative, and their relation to psychosocial adaptation in midlife adults and in students. Personality and Social Psychology Bulletin, 27, 472-483.

McCabe, A., Capron, E., \& Peterson, C. (1991). The voice of experience: The recall of early childhood and adolescent memories by young adults. In A. McCabe \& C. Peterson (Eds.), Developing narrative structure (pp. 137-174). Hillsdale, NJ: Erlbaum.
McLean, K. C. (2005). Late adolescent identity development: Narrative meaning-making and memory telling. Developmental Psychology, 41, 683-691.

McLean, K. C., \& Thorne, A. (2001). Manual for coding meaning-making in self-defining memories. Unpublished manuscript, University of California, Santa Cruz.

McLean, K. C., \& Thorne, A. (2003). Adolescents' self-defining memories about relationships. Developmental Psychology, 39, 635-645.

Meilman, P. W. (1979). Cross-sectional age changes in ego identity status during adolescence. Developmental Psychology, 15, 230-231.

Murray, H. A. (1938). Explorations in personality. New York: Oxford Press.

Pals, J. L. (in press). The narrative identity processing of difficult life experiences: Pathways of personality development and positive selftransformation in adulthood. Journal of Personality.

Pals, J. L., \& McAdams, D. P. (2004). The transformed self: A narrative understanding of posttraumatic growth. Psychological Inquiry, 15, 6569.

Pratt, M. W., Norris, J. E., Arnold, M. L., \& Filyer, R. (1999). Generativity and moral development as predictors of value-socialization narratives for young persons across the adult lifespan: From lessons learned to stories shared. Psychology and Aging, 14, 414-426.

Pratt, M. W., Norris, J. E., van de Hoef, S., \& Arnold, M. L. (2001). Stories of hope: Parental optimism in narratives about adolescent children. Journal of Social and Personal Relationships, 18, 603-623.

Rimé, B., Mesquita, B., Phillipot, P., \& Boca, S. (1991). Beyond the emotional event: Six studies on the social sharing of emotion. Cognition and Emotion, 5, 435-465.

Sankey, A. M., \& Young, R. A. (1996). Ego-identity status and narrative structure in retrospective accounts of parental career influence. Journal of Adolescence, 19, 141-153.

Scheier, M. F., \& Carver, C. S. (1985). Optimism, coping, and health: Assessment and implications of generalized outcome expectancies. Health Psychology, 4, 219-247.

Tedeschi, R. G., \& Calhoun, L. G. (2004). Target article: Posttraumatic growth: Conceptual foundations and empirical evidence. Psychological Inquiry, 15, 1-18.

Thorne, A., \& McLean, K. C. (2002). Gendered reminiscence practices and self-definition in late adolescence. Sex Roles, 46, 261-271.

Thorne, A., \& McLean, K. C. (2003). Telling traumatic events in adolescence: A study of master narrative positioning. In R. Fivush \& C. Haden (Eds.), Connecting culture and memory: The development of an autobiographical self (pp. 169-185). Mahwah, NJ: Erlbaum.

Thorne, A., McLean, K. C., \& Lawrence, A. (2004). When remembering is not enough: Reflecting on self-defining events in late adolescence. Journal of Personality, 72, 513-542.

Wang, Q. (2004). The emergence of cultural self-constructs: Autobiographical memory and self-description in European and American and Chinese children. Developmental Psychology, 40, 3-15.

Youniss, J., \& Smollar, J. (1985). Adolescent relations with mothers, fathers, and friends. Chicago: University of Chicago Press.

Received May 4, 2005

Revision received September 29, 2005

Accepted December 21, 2005 